\title{
Demonstration of Datacenter Automation Software and Hardware (DASH) at the California Franchise Tax Board
}

Geoffrey C. Bell, Lawrence Berkeley National Laboratory

Clifford Federspiel, Federspiel Controls

December 2009 


\section{DISCLAIMER}

This document was prepared as an account of work sponsored by the United States Government. While this document is believed to contain correct information, neither the United States Government nor any agency thereof, nor The Regents of the University of California, nor any of their employees, makes any warranty, express or implied, or assumes any legal responsibility for the accuracy, completeness, or usefulness of any information, apparatus, product, or process disclosed, or represents that its use would not infringe privately owned rights. Reference herein to any specific commercial product, process, or service by its trade name, trademark, manufacturer, or otherwise, does not necessarily constitute or imply its endorsement, recommendation, or favoring by the United States Government or any agency thereof, or The Regents of the University of California. The views and opinions of authors expressed herein do not necessarily state or reflect those of the United States Government or any agency thereof or The Regents of the University of California. 


\section{Acknowledgments}

This work was supported by the California Energy Commission's Public Interest Energy Research (PIER) Program, under Contract No. 500-02-004, and by the U.S. Department of Energy under Contract No. DE-AC02-05CH11231.

Special thanks are extended to Jim Durborough and Manuel Lujano of the California Franchise Tax Board for their participation in this project. Additional thanks are extended to William Tschudi of Lawrence Berkeley National Laboratory for technical assistance and oversight of the project.

Please cite this report as follows:

Bell, Geoffrey C., Cliff Federspiel. September 2009. Demonstration of Datacenter Automation Software and Hardware (DASH) at the California Franchise Tax Board California Energy Commission. 


\section{Table of Contents}

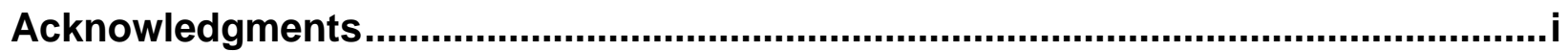

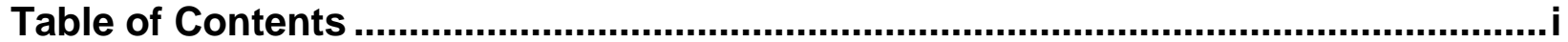

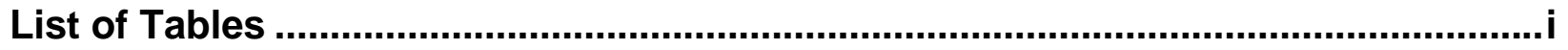

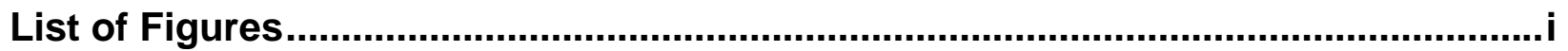

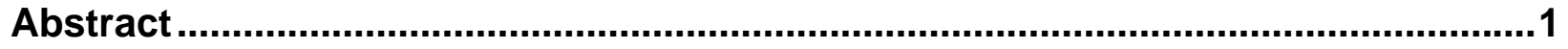

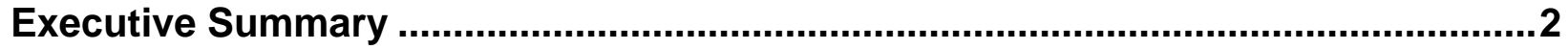

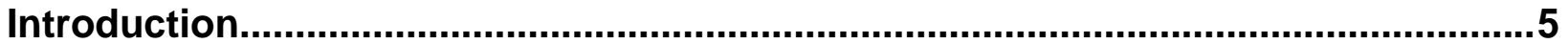

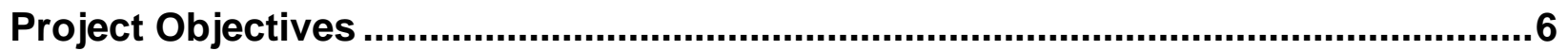

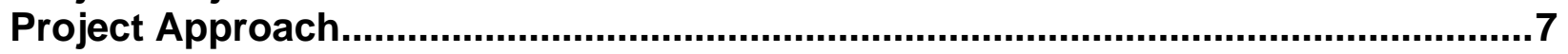

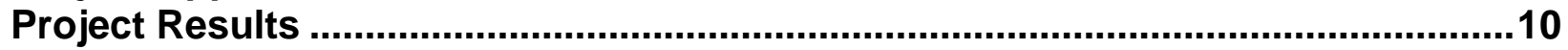

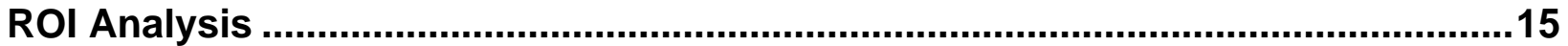

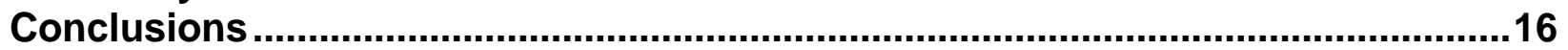

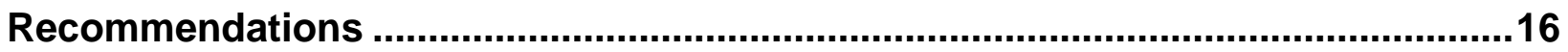

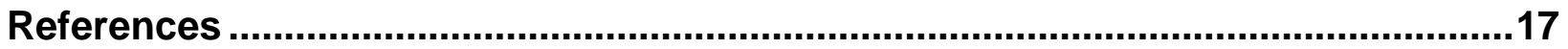

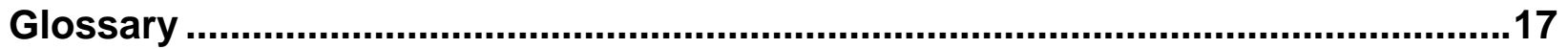

\section{List of Tables}

Table 1: ROI Analysis.

\section{List of Figures}

Figure 1: Floor plan with sensor locations.

Figure 2: Inlet air sensor.

Figure 3: CRAH sensor.

Figure 4: Open floor tiles.

Figure 5: VFD installed.

Figure 6: Control software interface.

Figure 7: Hot-aisle containment curtains.

Figure 8: Cold-aisle temperatures before/after each measure.

Figure 9: CRAH electrical energy consumption before/after each measure

Figure 10: PDU electrical energy consumption before/after each measure

Figure 11: Chilled water cooling energy consumption before/after each measure 


\begin{abstract}
Control software and wireless sensors designed for closed-loop, monitoring and control of IT equipment's inlet air temperatures in datacenters were evaluated and tested while other datacenter cooling best practices were implemented. The controls software and hardware along with each best practice were installed sequentially and evaluated using a measurement and verification procedure between each measure. The results show that the overall project eliminates $475,239 \mathrm{kWh}$ per year, which is $21.3 \%$ of the baseline energy consumption of the data center. The total project, including the best practices will save $\$ 42,772$ per year and cost $\$ 134,057$ yielding a simple payback of 3.1 years. However, the control system alone eliminates $59.6 \%$ of the baseline energy used to move air in the datacenter and $13.6 \%$ of the baseline cooling energy, which is $15.2 \%$ of the baseline energy consumption (see Project Approach, Task 1, below, for additional information) while keeping temperatures substantially within the limits recommended by ASHRAE. Savings attributed to the control system are $\$ 30,564$ per year with a cost $\$ 56,824$ for a simple payback of 1.9 years.
\end{abstract}

Key Words: control, data center, HVAC, wireless 


\section{Executive Summary}

\section{Overview}

ASHRAE [1] with agreement from manufacturers of IT equipment (servers, network equipment, and storage devices) have collectively recommended operating temperature ranges for inlet air to datacenter IT equipment. These server inlet recommendations for temperature are: $64.4-80.6{ }^{\circ} \mathrm{F}(18 \stackrel{\circ}{\circ} \mathrm{C}-27 \stackrel{\circ}{\circ} \mathrm{C})$, and for humidity $42-59{ }^{\circ} \mathrm{F}\left(5.5{ }^{\circ} \mathrm{C}-15\right.$ ${ }^{\circ} \mathrm{C}$ ) dew point (with a maximum $60 \%$ relative humidity). Although the cooling units in a datacenter may be networked for remote monitoring, they are normally controlled in a standalone, decentralized mode based on return air temperature to the cooling unit, rather than inlet air temperature to the servers. This often results in over-cooling, and contending (i.e., "fighting") unit controls, and thus wasting energy.

This demonstration project exhibits wireless sensor networks to control computer room air handlers and illustrates several best practices in addition to this technology. Combined, these measures can improve air distribution resulting in better temperature control while achieving dramatic energy savings. In this demonstration, a wireless mesh-network of temperature sensors was installed to provide temperature feedback at the inlet to the IT equipment. The mesh-network feedback was used as input to control software that automatically determines which cooling units to operate, and resets operating setpoints of the cooling units. Additional best practices included in this demonstration are: re-arrangement of floor tiles; installation of variable frequency drives on cooling unit fan motors; mounting of hot-aisle containment curtains; and filling server rack openings, a.k.a., blanking.

\section{Demonstration Sequence}

The project was implemented with a measurement and verification period after each step to determine the sequential impact of each measure. The demonstration proceeded in the following order:

1. Installing wireless temperature sensors and power-monitoring data loggers and meters to provide baseline energy-use data.

2. Repositioning floor tiles to improve air distribution.

3. Retrofitting computer room air handling (CRAH) units with Variable Frequency Drives (VFDs) to modulate fan operation.

4. Installing and commissioning automated software to provide temperature control.

5. Mounting flexible curtains to isolate server hot-aisle airflow.

6. Filling openings in server racks with blanking plates or covers to eliminate airflow "short circuits" through the racks.

The following provides details for each sequential step:

Step 1: Twenty-three (23) wireless temperature sensor modules were installed each with two sensing positions, one near the top of a rack and one near the bottom. A wireless temperature sensor module was installed on each computer room air-handler and at the chilled water main for the datacenter to enable measurement of supply and return water temperature. An ultrasonic flow meter was installed to measure chilled 
water flow, and a wireless flow sensor module was used to monitor the output of the flow meter. An electric power data logger was installed on the main breaker panel feeding the CRAHs to monitor total electrical energy consumption of the CRAHs.

Step 2: Additional floor tiles were procured and installed that prevented air from being discharged from the raised floor at locations outside of the cold aisles or away from IT equipment.

Step 3: A representative from the cooling unit equipment manufacturer installed variable frequency drive (VFD) kits on the supply air fans in four of the $12 \mathrm{CRAH}$ units. These kits integrated the VFDs with existing embedded controllers in the CRAH units.

Step 4: Supervisory control software was installed and commissioned that reset return air temperature setpoints of the CRAH units via a gateway that supports BACnet/IP. The supervisory control software also starts and stops CRAH units via the same gateway. Control decisions are made based on cold aisle temperature readings from the wireless sensors.

Step 5: Special strip curtains (with fusible links) were installed to isolate rejected hot air from server racks, i.e., hot-aisles, without mixing with the cooled air within the data center ${ }^{1}$. These hot-aisles are connected to the existing overhead plenum that returns the hot air to the inlet of the CRAHs.

Step 6: The facilities staff with Franchise Tax board filled, i.e., blanked, openings in the server racks to prevent short-circuits between the hot-aisles and cold-aisles directly through the racks.

\section{Project Results}

The project achieved five significant results:

1) Re-arranging floor tiles reduced and stabilized cold-aisle temperatures by improving air distribution, which resulted in a large reduction in chilled-water energy consumption. Re-arranging the floor tiles did not change the electrical consumption of the CRAHs or of the IT equipment, but it appears to have reduced the chilled water energy consumption for an equivalent of $44,496 \mathrm{kWh}$ per year. Further discussion is provided regarding main building air-handling system impact on achieving this reduction, see Project Results, Result 1: Floor tile changes, below.

2) The VFDs slightly decreased the cold-aisle temperatures, since operation at slower fan speeds resulted in more effective cooling of the airflow across the cooling coils. This increased effectiveness and slower fan speeds slightly increased the variability of the cold-aisle temperatures. In sum, the VFD controlled fans reduced electrical energy consumption of the CRAHs and further reduced chilled water energy consumption.

3) The control software increased the average cold-aisle temperature, while maintaining $97 \%$ of all temperature readings below the upper limit of the recommended range of ASHRAE. The control software eliminated $59.6 \%$ of the baseline fan energy (and $63 \%$

\footnotetext{
${ }^{1}$ Fire codes and local jurisdictions prohibit barriers that could disrupt sprinkler operation. These strip curtains are specially designed to attach to ceiling grids using fusible links that will automatically drop the curtains out of the sprinkler paths in the event of a fire.
} 
of the fan energy from the previous step). The control software eliminated $13.6 \%$ of the baseline chilled water consumption (and $18.3 \%$ of the chilled water consumption from the previous step).

4) Hot-aisle containment had a small impact on cold aisle temperatures. Initially, the installation resulted in an increase in fan energy consumption because un-blanked areas of the server racks allowed some hot-aisle air to flow directly back into the cold aisles. This short-circuiting of hot air affected the cold aisle temperature and, in response, the control software operated more CRAH units to maintain cold-aisle temperature distribution. Hot-aisle containment significantly increased the overhead plenum temperatures, with sensor readings as high as $89^{\circ} \mathrm{F}\left(32^{\circ} \mathrm{C}\right)$.

5) Once the server racks had all "blanks" installed, the control software was able to reduce the number of operating CRAH units, thus reducing fan energy consumption to a slightly lower average level than before the hot aisle containment was installed. The biggest impact of hot aisle containment was raising the return air temperatures, which increased the capacity of the CRAHs. Since there was already significantly more cooling capacity in the data center than necessary, the increased capacity of hot aisle containment did not have a large impact on energy savings; however, in a more densely populated data center, benefits from aisle containment should be more significant.

Overall, the control software had the biggest impact on reducing data center energy. Rearranging the floor tiles resulted in the biggest change in chilled water energy consumption (followed by the control software), but confounding factors such as heat exchange with the building air-handling system or manual control of the cooling units could have contributed to the observed changes in chilled water consumption.

\section{Recommendations}

In future deployments, we recommend that the sensors and control software be installed first. This would provide the highest initial savings and best initial return on investment, and would provide detailed information about how to cost-effectively deploy other best practices.

Additional studies of the impact of air distribution, particularly floor tile arrangement, is warranted given the large change in chilled water consumption that coincided with rearranging the floor tiles in this data center. Also, additional studies on the means and benefits of raising chilled water temperatures is warranted given the fact that we were able to raise return temperatures by $7{ }^{\circ} \mathrm{F}(3.9 \stackrel{\circ}{\circ})$. Finally, additional studies on the means and benefits of complementing the elevated data center temperatures with free cooling is warranted. For example, at this site the datacenter is served by three terminal units from the main building air handler, which has an air-side economizer. A study of how to use the free cooling resources of the main air handler best for the datacenter and integrating those cooling control actions with the control of the CRAHs is warranted since many datacenters are located in larger facilities where some cooling could be provided by conventional air handlers with air-side economizers. 


\section{Introduction}

\section{Project Overview}

The combined effect of overcooling, fighting instabilities, and non-uniform or variable loads in datacenters has generated a need for more accurate control of datacenter cooling. This case study demonstrates the use of wireless sensor networks for supervisory control combined with improved air-distribution best-practices in an enterprise datacenter. The datacenter is a 10,000 square foot $\left(929 \mathrm{~m}^{2}\right)$ raised-floor room at the California Franchise Tax Board. The datacenter is cooled by twelve (12) 22ton computer room air-handling (CRAH) units that each have chilled water cooling. The CRAHs have reheat and infrared humidifiers, but these capabilities are normally disabled by the operations staff. The CRAH units deliver air to a raised-floor plenum. The datacenter has an overhead plenum, but it was not used for return air to the CRAH units. The datacenter was originally built out to 40 percent of capacity with 77 racks, but a virtualization effort prior to the start of the project reduced the IT load delivered from the UPS to $143 \mathrm{~kW}$. The exact IT load before the virtualization effort is not known.

\section{Monitoring Network}

A wireless mesh network of temperature sensors was installed to provide inlet air temperature feedback. The mesh network feedback was used to determine which cooling units to operate, and to reset the setpoints of the operating cooling units. Interfacing the wireless supervisory control system with the cooling unit controls was facilitated by the open communication protocol of the cooling and power units in the datacenter. Some of the cooling units were converted to variable-speed operation with variable frequency drive retrofits. In addition to correcting air distribution degradation, containment curtains were added that separated hot air from cold air in the aisles to allow the cooling units to draw heated return air from an overhead plenum. Energy and environmental control improvements of the supervisory control system were documented, including the impact of variable-speed fan operation and separation of hot air from cold air using strip-type curtains. Energy and thermal performance was documented using a before-after measurement and verification approach that included component energy monitoring for a two-week period before and after installation.

\section{Overcooling}

ASHRAE [1] and IT equipment manufacturers (servers, network equipment, and disk drives) have collectively reached consensus on recommended environmental operating ranges for datacenter IT equipment air inlet conditions of 64.4-80.6 degF and 42-59 degF dew point (with a maximum 60 percent relative humidity). To operate datacenter IT equipment at the recommended temperature range, cooling units are often placed throughout datacenters. The cooling units also have on-board digital controls and embedded sensors that measure temperature and humidity of the air returning to the cooling unit. The digital controls in the cooling units operate to keep the 
return air temperature and humidity close to values set manually by an operator. Placing the temperature control in the return to the air handler creates a source of confusion for the data center operators who often think this is a supply temperature. Since the cooling unit controls do not monitor the server inlet air temperature, data center operators have a tendency to set the cooling unit's setpoint too low to ensure that the hottest server equipment is satisfied, thereby causing overcooling and, consequently, wasting energy. Overcooling also may adversely affect IT equipment reliability. Google ${ }^{\circledR}$ recently reported that very cold datacenter temperatures increase the annual failure rate of disk drives [2]. At the FTB, the baseline IT load was $143 \mathrm{~kW}$ measured at the center's uninterruptible power supply (UPS). The installed cooling capacity is 240 tons, which is $840 \mathrm{~kW}$; therefore, 5.9-times more capacity than the measured IT load is available, which is higher than average, compared to other situations.

\section{Contending Control}

Although the cooling units in a datacenter may be networked for remote monitoring, they are normally controlled in a standalone, decentralized mode. This often causes "fighting" between cooling units. One unit may be trying to humidify, which causes another nearby unit to cool more, and in doing so condense moisture from the air, which causes the humidifying unit to work harder, and so on. As IT equipment density increases, cooling units are getting closer together, which results in more fighting. At the FTB, most of the time humidity control and reheat is turned off, so there is generally no contending between humidity control and temperature control. However, supply air temperature oscillations were recorded, due to interactions between CRAHs.

\section{Variable Loads}

According to the EPA and recent research at LBNL, datacenter loads are growing at a rate of 15 percent annually in the U.S., and at higher rates in developing countries such as China. Rapid load growth requires the construction of new datacenters, which are generally operated at a low load initially. Recent emphasis on IT resource demands and energy consumption in datacenters has resulted new technologies such as virtualization and dynamic load allocation that can dramatically reduce the load while making the loads highly variable. Therefore, this combination of new datacenter construction and IT technologies result in datacenters that have low, non-uniform, or dynamic cooling loads.

\section{Project Objectives}

The project objectives were as follows:

- Demonstrate wireless technology for direct control of data center air handlers

- Evaluate supervisory control software and hardware for datacenter cooling,

- Evaluate three best-practices for datacenter cooling and air management for energy and control of environmental conditions, 


\section{Project Approach}

The technical work was divided into four tasks.

Task 1. Installation of wireless sensors and power-monitoring datalogger A set of 23 wireless sensor modules, each with two thermistor probes were installed to measure inlet air temperatures at 46 locations. Figure 1 shows the data center floorplan with the location of the sensing and monitoring devices. Figure 2 shows a typical inlet air sensor installation. Additionally a wireless sensor module was installed to on each CRAH to measure the chilled water supply and return temperature as shown in Figure 3. An ultrasonic flow meter was installed to measure chilled water flow rate to the 12 CRAHs on the main floor plus the two smaller CRAHs in the UPS room, and a wireless sensor module was installed to measure the output of the ultrasonic flow meter. A data-logger was installed to measure the total power consumption of all $14 \mathrm{CRAHs}$ in the datacenter. The datacenter was monitored for a period of two weeks to establish the baseline condition.

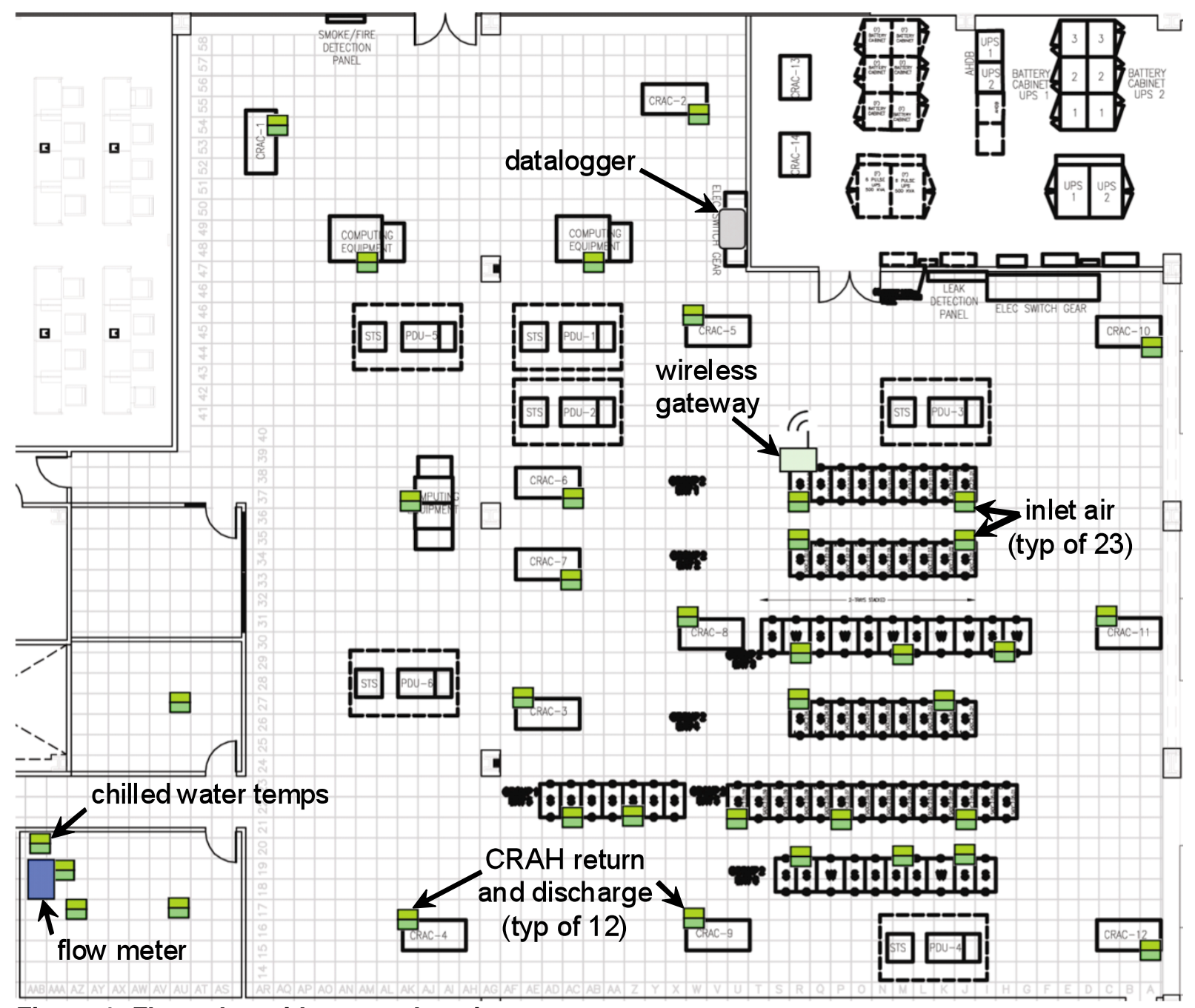

Figure 1: Floor plan with sensor locations. 


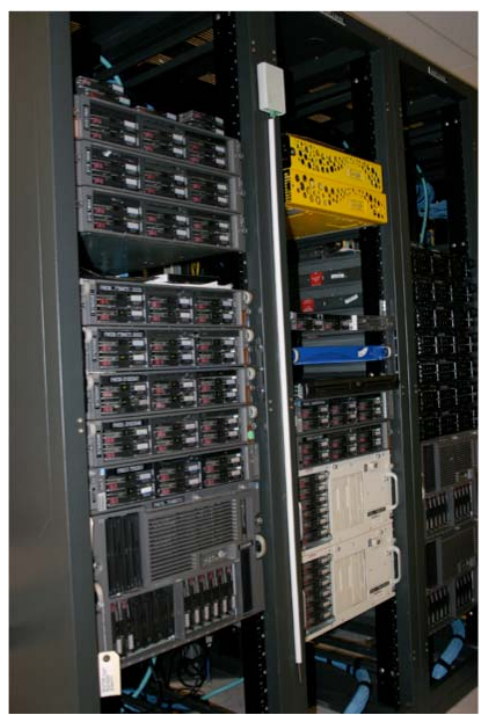

Figure 2: Inlet air sensor.

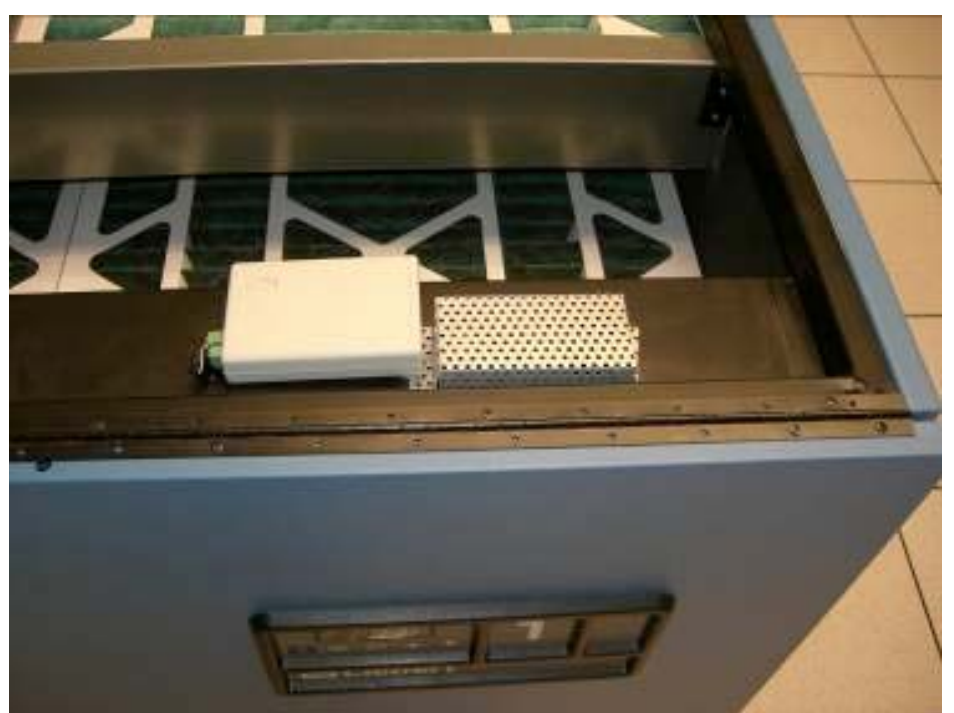

Figure 3: CRAH sensor.

Task 2. Improvement of air distribution by re-configuring floor tiles

The datacenter was designed with wellorganized hot and cold aisles and seals for the raised-floor penetrations. However, continual changes to the datacenter resulted in degradation of the air distribution including improperly located floor grills as shown in Figure 4. The first task involved replacing the open floor grills with closed floor grills so that cold air is only delivered to the front of the IT equipment. After reconfiguring the floor grills, datacenter temperatures and power measurements were recorded for a two-

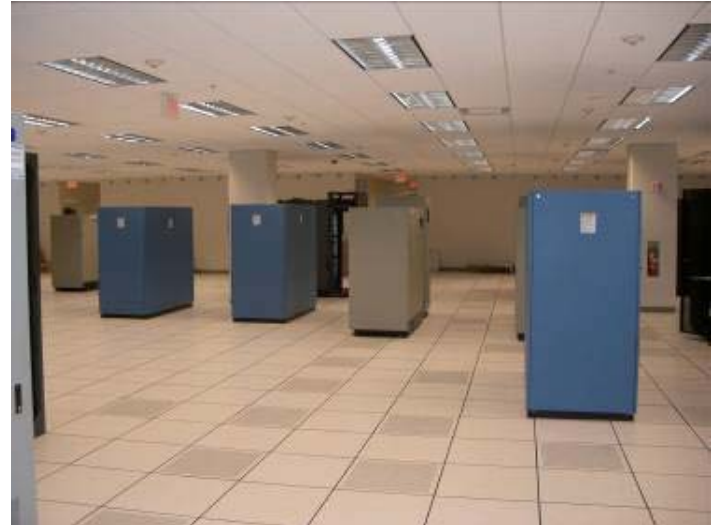

Figure 4: Open floor tiles. week period.

Task 3. Installation of Variable Frequency Drives

All twelve CRAHs in the data center had fixed-speed motors prior to this project. Variable frequency drives (VFDs) were installed on the four CRAHs closest to the main cluster of racks in the datacenter. Figure 5 shows a typical installation. The VFDs were integrated with the existing controls in the CRAHs so that the speed command followed the chilled water valve for its $\mathrm{CRAH}$.

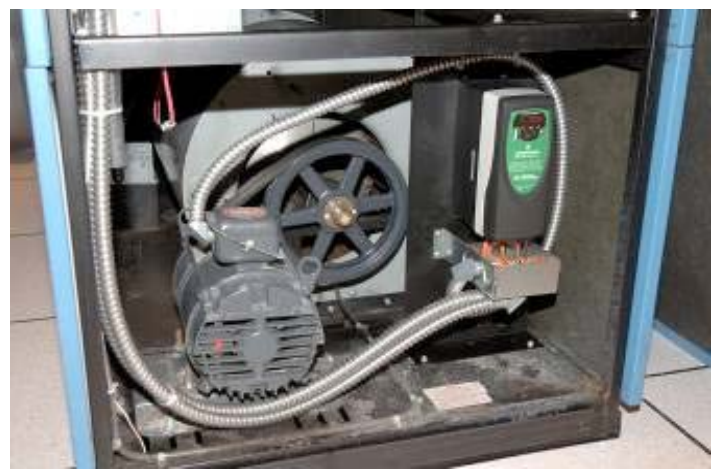

Figure 5: VFD installed. 
Task 4. Installation and commissioning of control software

The cooling units in the datacenter have embedded digital controllers that are networked via a gateway. The gateway supports BACnet/IP. BACnet is a data communications protocol for building automation and control networks. It is an ASHRAE, ANSI, and ISO standard protocol. BACnet/IP is a variant of BACnet that uses Internet Protocol for the data link layer.

The datacenter supervisory control software was installed and commissioned. Commissioning included interfacing with the cooling unit gateway via BACnet/IP. The control software reset the cooling unit setpoints, and turned off (and on) cooling units that did not need to run.

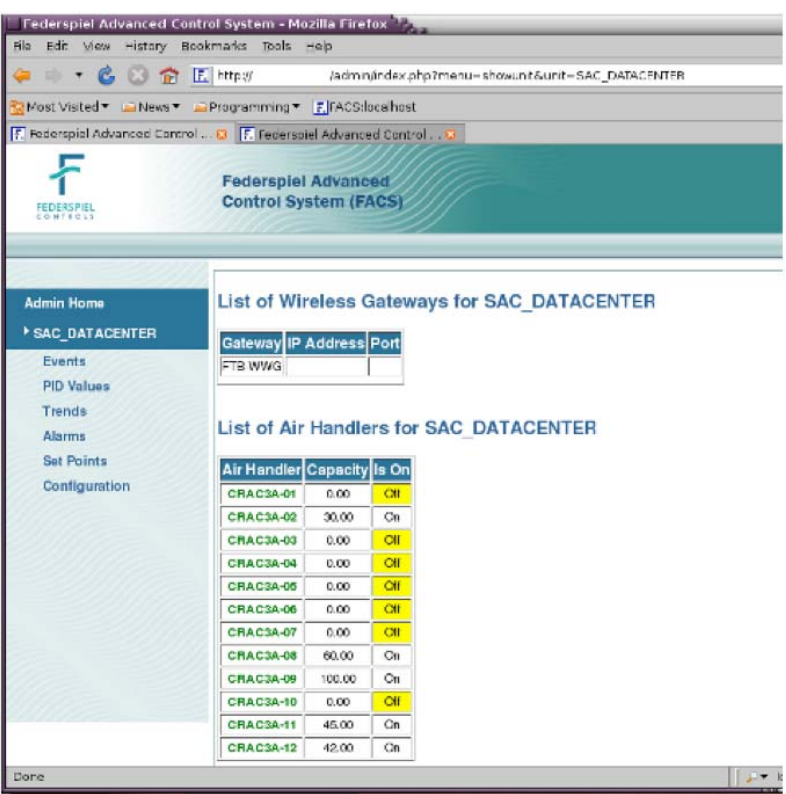

Figure 6: control software interface.

Figure 6 shows a screen shot of a web page at a time when the control software had seven of the 12 CRAHs off. After commissioning, the datacenter was monitored for two weeks.

Task 5. Installation of hot aisle containment curtains

Strip curtains were installed to isolate the hot aisles, and to connect the inlet of the cooling units to the overhead plenum. The strip curtains were attached to the "t-bar" ceiling with fusible links that would cause the curtains to drop in the event of a fire so that the sprinkler system would work as designed in that event. Figure 7 shows the containment curtains.

Task 6. Blanking of openings in the racks

Many of the racks had large sections that were not occupied by IT equipment, but were not blanked off. As a result, air from the hot aisle was flowing through the racks into the cold aisles in some locations. The large openings in the racks were blanked with excess strip curtain materials from Task 5 , while small openings were blanked with

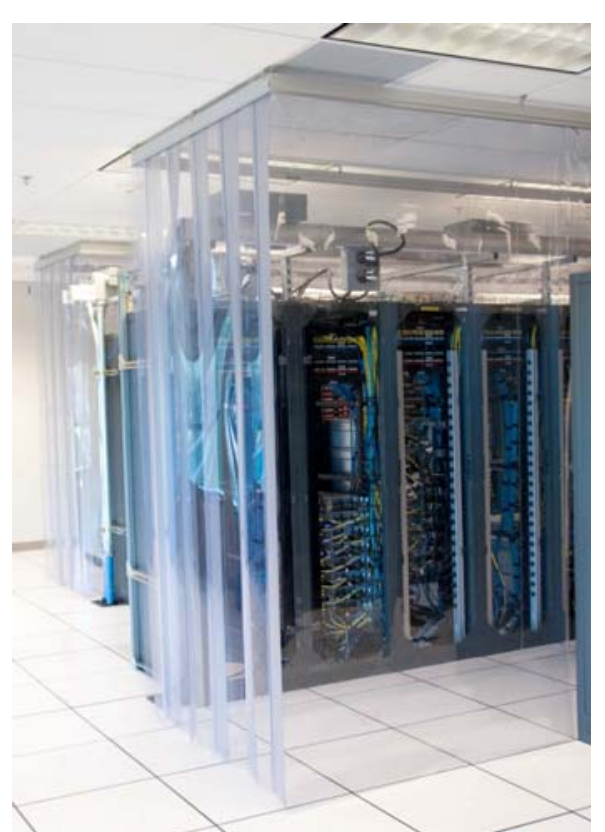

Figure 7: hot-aisle containment curtains. conventional blanking plates. 


\section{Project Results}

Analyses began with "box-and-whisker" plots of cold-aisle temperatures, electric energy consumption of the cooling units, IT electric energy consumption, and cooling (chilled water) energy consumption (Figures 8 through 11). Box-and-whisker symbols in each figure correspond to the time intervals before and after when each cooling best practice was implemented. The top of each top whisker is the maximum value (temperature, $\mathrm{kW}$, or tons) for that time interval, the top of each box is the $75^{\text {th }}$ percentile for that interval, the dash in the middle of each box is the median, the bottom of each box is the $25^{\text {th }}$ percentile for that interval, and the bottom of each bottom whisker is the minimum for that interval as follows:

- Interval A, before Task 1 (baseline).

- Interval B, between Task 1 and Task2

- Interval C, after Task 2 but before Task 3

- Interval D, after Task 3 but before Task 4

- Interval E, after Task 4 but before Task 5 and

- Interval F, all Tasks complete.

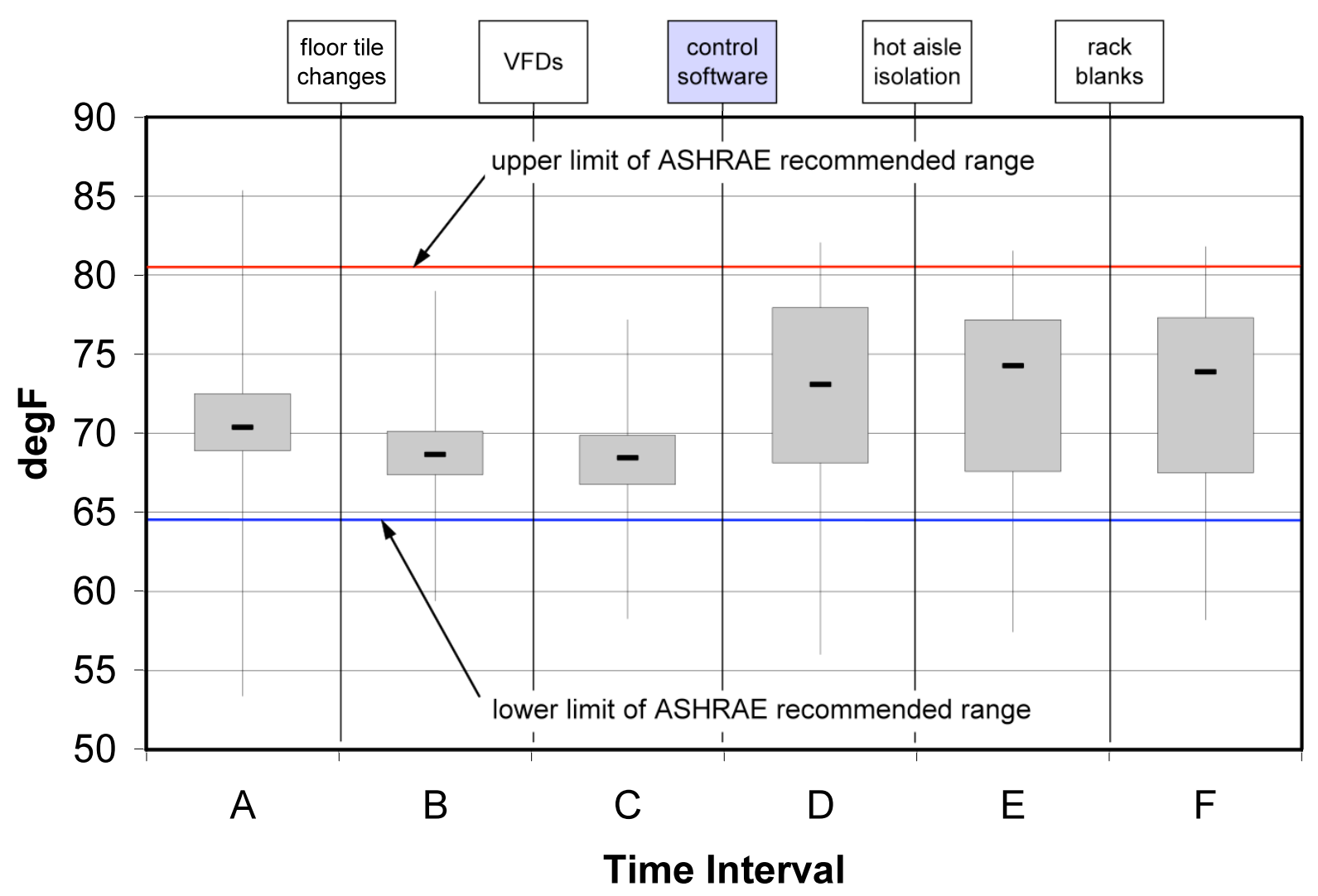

Figure 8: Cold aisle temperatures before/after each measure. 


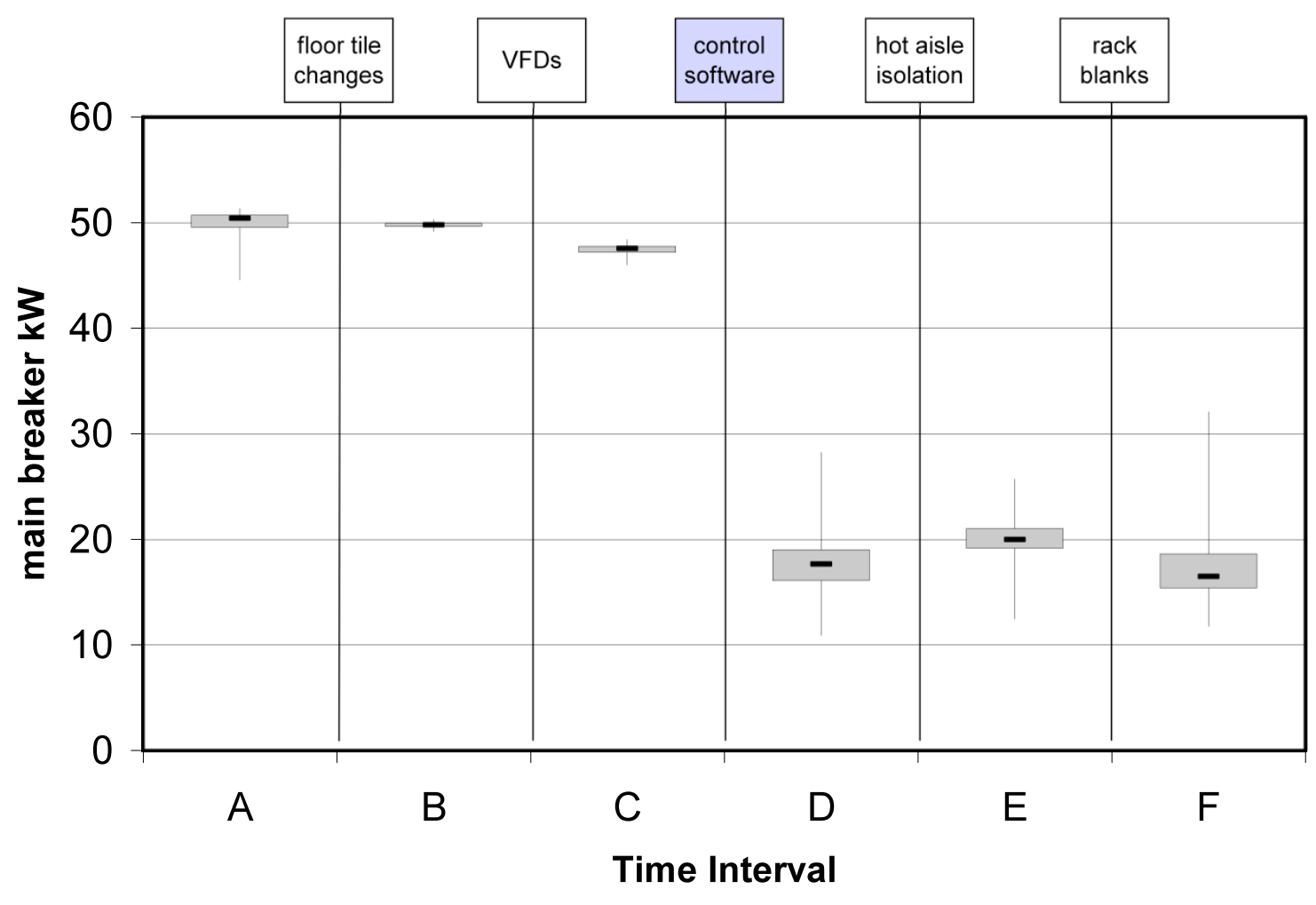

Figure 9: CRAH electrical energy consumption before/after each measure

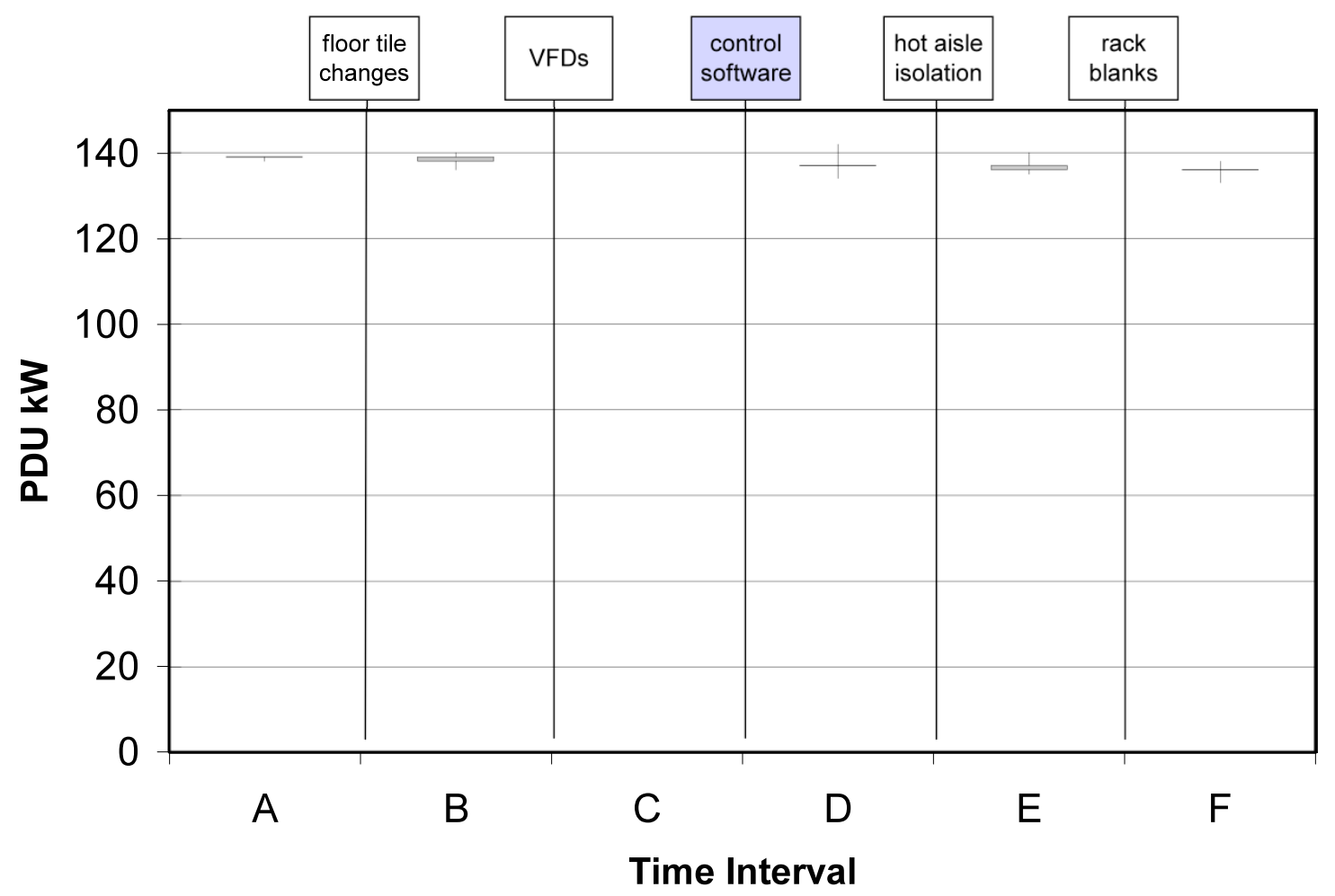

Figure 10: PDU electrical energy consumption before/after each measure 


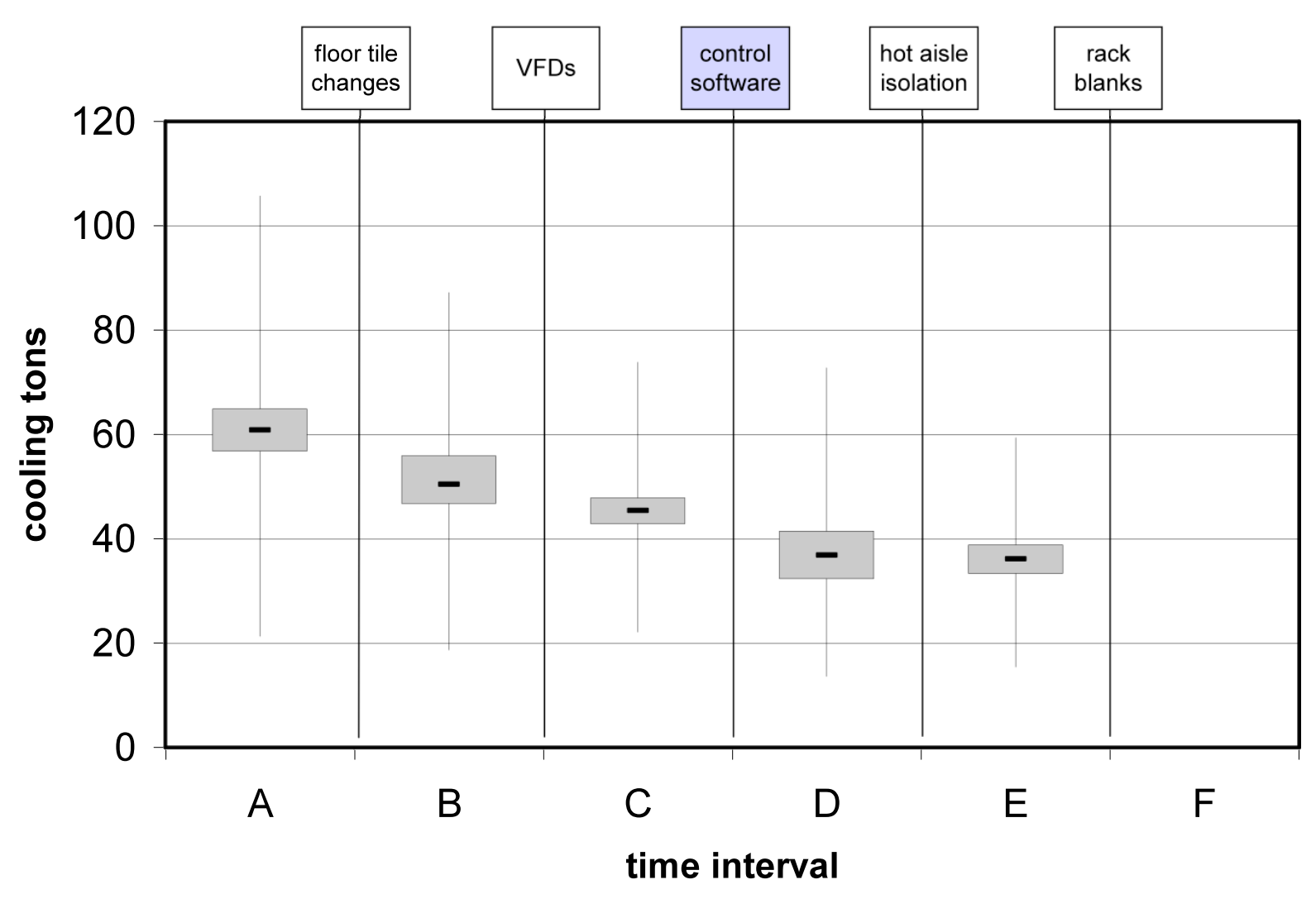

Figure 11: Chilled water cooling energy consumption before/after each measure

\section{Result 1: Floor tile changes.}

Closing open floor tiles lowered average cold aisle temperature by $1.6 \stackrel{\circ}{\circ}\left(0.9{ }^{\circ} \mathrm{C}\right)$ from 70.3 to $68.7 \mathrm{deg} F,\left(21.3^{\circ} \mathrm{C}-20.4{ }^{\circ} \mathrm{C}\right)$ and decreased the range between the $75^{\text {th }}$ percentile and the $25^{\text {th }}$ percentile by $0.9^{\circ} \mathrm{F}\left(0.5^{\circ} \mathrm{O}\right)$. Spot measurements of the underfloor plenum pressure before and after closing the floor tiles showed that the plenum pressure increased from a range of 2-3 $\mathrm{Pa}(0.008$ to 0.0012 in w.g.) to a range of $12-14$ $\mathrm{Pa}(0.048$ to 0.056 in. w.g.). As expected, closing the floor tiles had no effect on the electrical energy consumption of the CRAHs, and no effect on the electrical energy consumption of the IT equipment.

The average chilled water cooling decreased from 60.8 tons to 51.1 tons $(213.8 \mathrm{~kW}$ to $179.7 \mathrm{~kW}$ ). It is not entirely clear whether closing the open floor tiles caused this reduction. Since the datacenter is lightly loaded $\left(14 \mathrm{~W} / \mathrm{sf}\left(150 \mathrm{~W} / \mathrm{m}^{2}\right)\right.$ IT load), the reduction may have been due to weather changes or changes in chilled water temperature (which could affect cooling coil condensation). However, after compensating for outdoor air temperature, outdoor air dew point, wind, and chilled water temperature using linear regression analysis, the difference persisted. It is possible that a confounding factor that could not be measured, such as operations staff manually changing CRAH setpoints or changing the operation of the main building air-handling system could have accounted for the reduction in chilled water consumption. 


\section{Result 2: VFD Installations}

Six weeks after the CRAH VFDs had been installed, it was discovered that they were operating at a fixed speed of $34 \mathrm{~Hz}$ due to a firmware "bug" in the VFDs. Since the load on the CRAHs was low, the energy performance under normal VFD operation would have been similar to the low "fixed-speed" VFD operation, i.e., the speed of $34 \mathrm{~Hz}$ is about the same as the normal minimum speed of $36 \mathrm{~Hz}$ during normal operation (speed without a VFD is $60 \mathrm{~Hz}$, and maximum speed with a VFD is $60 \mathrm{~Hz}$ ). It is assumed that the energy performance measured during Interval $C$ was about what it would have been without the firmware bug. The VFD firmware was corrected at the same time that the supervisory control software was commissioned.

The reduced speed of the CRAH fans with VFDs lowered the average cold aisle temperature slightly, from $68.7^{\circ} \mathrm{F}$ to $68.4{ }^{\circ} \mathrm{F}\left(20.4{ }^{\circ} \mathrm{C}-20.2^{\circ} \mathrm{C}\right)$, and increased the range between the $75^{\text {th }}$ percentile and the $25^{\text {th }}$ percentile slightly, by $0.4{ }^{\circ} \mathrm{F}\left(0.2{ }^{\circ} \mathrm{C}\right)$.

The reduced speed of the four CRAH fans decreased the total CRAH electrical energy consumption by $2.3 \mathrm{~kW}$, from 49.8 to $47.5 \mathrm{~kW}$ (IT electrical energy consumption trends were missing during this period). This reduction is significantly less than would have been anticipated from a power law analysis of the fan speed. However during the VFD installation, the fan belts were replaced and re-tightened, with the contractor noting that the belts were very worn and loose. The new belts may have caused the motors to move more air, which may have offset some savings. Additionally, the belts on the other CRAHs were checked when the loose belts were discovered on the four retrofit units, and the belts on one of the remaining eight were tightened, which may have been an additional confounding factor.

The VFD installation coincided with a decrease in chilled water energy consumption of 5.7 tons $(20 \mathrm{~kW})$, which is nearly 10 times the fan power load reduction caused by the VFDs. This suggests a potential confounding factor affecting chilled water energy consumption.

\section{Result 3: Supervisory control software}

The control software raised the return temperature setpoints by about $7{ }^{\circ} \mathrm{F}(3.9 \stackrel{\circ}{\circ} \mathrm{C})$ over the values used during intervals A, B, and C, and turned off from five (5) to seven (7) CRAHs at any given time. Note that by simply turning off unneeded capacity, the control system demonstrates its immediate benefit and ability to reduce energy waste. Figure 5 shows a screen shot of the web interface at a point in time when the software had turned off seven (7) of the twelve (12) CRAHs. These control actions raised the average cold aisle temperature to $72.5^{\circ} \mathrm{F}\left(22.5^{\circ} \mathrm{C}\right)$, and increased the range between the $75^{\text {th }}$ percentile and the $25^{\text {th }}$ percentile significantly, to $9.8^{\circ} \mathrm{F}\left(5.5^{\circ} \mathrm{C}\right)$. The maximum recorded cold aisle temperature was $82.1^{\circ} \mathrm{F}\left(27.8^{\circ} \mathrm{C}\right)$, which was $3.3^{\circ} \mathrm{F}\left(1.9^{\circ} \mathrm{O}\right)$ lower than the maximum cold aisle temperature recorded during the baseline period. During Interval D, $97 \%$ of the cold aisle temperature readings were below the recommended upper limit of ASHRAE.

The control software decreased the total fan power by $29.9 \mathrm{~kW}$, which is $59.6 \%$ of the baseline fan power (and $63 \%$ of the fan power from Interval C). The measured fan power includes the power of the two CRAHs that serve the UPS room (they were not controlled by or affected by any of the installed measures). 
The PDU power decreased by $1.7 \mathrm{~kW}(1.2 \%)$, but it isn't clear if the reduction was caused by the effects of the control software. It is possible that servers or other IT loads were removed or reprogrammed between the baseline interval $(A)$ and the post control software monitoring interval (D).

The cooling energy consumption decreased by 8.3 tons, from 45.3 tons to 35.0 tons (159.3 kW to $123 \mathrm{~kW}$ ). This decrease, when converted to $\mathrm{kW}$, is nearly identical to the fan power reduction achieved by the control software.

\section{Result 4: Hot aisle containment}

Strip curtains were used to isolate, i.e., contain, the hot aisles and connect the CRAH air returns to the overhead plenum so that the hot-aisle air could return to the CRAHs without mixing with the cold-aisle air.

The hot-aisle containment had a negligible impact on the cold-aisle temperature distribution, but this is primarily because the control software was running and responding to the cold-aisle temperature distribution. The warmest cold-aisle temperature was just $0.5^{\circ} \mathrm{F}\left(0.3^{\circ} \mathrm{C}\right)$ lower than the hottest recorded during the precontainment monitoring interval.

The hot-aisle containment installed, before blanking plates were also installed, increased the average fan energy consumption because without rack blanks, the control software caused more CRAH units to run in order to maintain the cold-aisle temperature distribution. The strip curtains had a negligible impact on PDU energy consumption.

Cooling energy consumption decreased by 0.9 tons $(3.2 \mathrm{~kW})$ after the hot-aisle containment was installed. This reduction was achieved despite the fact that the fan energy consumption, which is a load on the chilled water, increased. The overhead plenum is not sealed at the boundary of the datacenter, so the cooling energy savings may have been achieved by transferring some of the heat to the main air-handlers serving the rest of the building.

After the hot-aisle containment was installed, return plenum temperature sensors that were a pre-existing component of the building management system were monitoring $89{ }^{\circ} \mathrm{F}\left(31.6^{\circ} \mathrm{C}\right)$ in the plenum. This demonstrates the benefit of the containment curtains. It also provides additional evidence for a transfer of cooling energy to the main air-handlers because the return air temperature at the CRAH inlets was significantly lower, typically below $80^{\circ} \mathrm{F}\left(27^{\circ} \mathrm{C}\right)$.

\section{Result 5: Rack blanks}

After the hot-aisle containment was installed, the racks were blanked. Small openings were blanked with conventional rack blanks, and large openings were blanked with left over material used to connect the CRAHs to the overhead plenum.

The rack blanks had a negligible impact on the cold aisle temperature distribution. The maximum hot-aisle temperature recorded during the post-blank time interval was $81.8{ }^{\circ} \mathrm{F}\left(27.7^{\circ} \mathrm{O}\right)$, which was $0.3^{\circ} \mathrm{F}\left(0.1^{\circ} \mathrm{C}\right)$ higher than the maximum recorded during the pre-blank monitoring interval.

The rack blanks allowed the control software to reduce the CRAH power to approximately the level prior to hot-aisle containment. The average CRAH fan power was $17.3 \mathrm{~kW}$, which is $0.3 \mathrm{~kW}$ lower than the fan power prior to hot aisle containment. 
The average PDU energy consumption was slightly lower after blanking (135.0 kW) than before blanking $(136.7 \mathrm{~kW})$ or before hot-aisle containment $(137.1 \mathrm{~kW})$, but all of these small changes could easily be due to minor changes in IT equipment or processes, and unrelated to the installed measures.

\section{ROI Analysis}

Annual energy savings and cost savings were estimated based on the following assumptions:

1. Mechanical cooling efficiency equal to $1.0 \mathrm{~kW} /$ ton

2. Economizer cooling efficiency for the main building AHUs equal to $0.32 \mathrm{~kW} /$ ton

3. $\$ 0.09 / \mathrm{kWh}$ utility rate

The VFDs and control software eliminated data center load by reducing fan speeds and turning CRAHs off. For the measures that did not directly eliminate some of the data center cooling load (re-arranging floor tiles and hot aisle containment), we assumed that the cooling energy savings were achieved by transferring cooling load to the main air-handlers in the building. This saves energy because the main air-handlers have economizer cooling capability, and economizer cooling only uses about one-third of the energy of mechanical cooling. For the VFDs, the measured reduction in cooling energy exceeded the amount that could be attributed to the direct elimination of fan energy, so the cooling energy that exceeded that which could be attributed to fan energy reduction was assumed to have been transferred to the main air-handlers. The cooling energy savings of the control software closely matched the eliminated fan energy.

For the transferred cooling energy, we estimated that there are 3694 hours per year when full economizer cooling is available (outdoor air less than $55^{\circ} \mathrm{F}\left(13^{\circ} \mathrm{C}\right.$ )), and 3280 hours per year when partial economizer cooling (outdoor air between $55^{\circ} \mathrm{F}\left(13^{\circ} \mathrm{C}\right.$ ) and $70{ }^{\circ} \mathrm{F}\left(22^{\circ} \mathrm{C}\right)$ ) is available. This means that $60.9 \%$ of the transferred cooling energy is from economizer cooling with an efficiency of $0.32 \mathrm{~kW} /$ ton rather than the mechanical cooling efficiency of $1.0 \mathrm{~kW} / \mathrm{ton}$.

The following table shows the savings and cost of each installed measure. The costs are the invoiced amounts. For the control system, an expected commissioning cost was added since commissioning was not invoiced to the project but normally would be.

Table 1: ROI analysis

\begin{tabular}{|l|r|r|r|r|r|}
\hline \multicolumn{1}{|c|}{ Measure } & \multicolumn{1}{c|}{ Cost } & $\mathrm{kWh} / \mathrm{yr}$ saved & $\%$ saved & \multicolumn{1}{c|}{$\$$ saved } & payback \\
\hline re-arrange tiles & $\$ 3,000$ & 44,496 & $2.0 \%$ & $\$ 4,005$ & 0.7 \\
\hline VFDs & $\$ 16,040$ & 75,135 & $3.4 \%$ & $\$ 6,762$ & 2.4 \\
\hline control system & $\$ 56,824$ & 339,603 & $15.2 \%$ & $\$ 30,564$ & 1.9 \\
\hline hot aisle containment & $\$ 58,193$ & 16,005 & $0.7 \%$ & $\$ 1,440$ & 40.4 \\
\hline TOTAL & $\$ 134,057$ & 475,239 & $21.3 \%$ & $\$ 42,772$ & 3.1 \\
\hline
\end{tabular}


The floor tiles have the shortest simple payback, but also the second-lowest savings. Also, the cost of the floor tiles was for "used" tiles; new tiles would have cost approximately $\$ 5,000$.

The VFDs were the second-least expensive, and resulted in the second-highest savings, with a simple payback of 2.4 years.

The control system achieved most of the savings. The measures installed prior to the control system were likely not necessary for the control system to reduce energy waste because the control system did not directly affect the CRAH fan VFD speeds. Significantly, the control system savings were achieved by turning off unnecessary CRAH units. It is possible that some control system savings could not have been achieved without re-arranging floor tiles.

The hot-aisle containment did not result in significant energy savings, but it did clearly capture the hot aisle air, raising temperature in the overhead plenum to $89^{\circ} \mathrm{F}$ $\left(32^{\circ} \mathrm{C}\right)$. This could significantly increase the cooling capacity of the CRAHs, which could be very important in a data center that is constrained by limited cooling capacity.

\section{Conclusions}

This demonstration project exhibits how wireless sensors combined with control software can be used effectively to improve temperature distribution and reduce energy use in data centers. In addition to demonstrating how this technology can be used, specific "best practice" measures were implemented. These measures are readily implemented in most conventional data centers and can result in significant energy savings with relatively short ROI (return on investment). Although the goal of this demonstration was not to optimize all available opportunities (e.g. raising chilled water temperature), substantial energy savings were achieved. The overall project eliminates $475,239 \mathrm{kWh}$ per year, which is $21.3 \%$ of the baseline energy consumption of the data center. The total project, including the best practices saves $\$ 42,772$ per year and cost $\$ 134,057$ for a simple payback of 3.1 years.

The control system alone eliminated $59.6 \%$ of the baseline energy used to move air in the datacenter, $13.6 \%$ of the baseline cooling energy, which is $15.2 \%$ of the total baseline energy consumption of the data center while keeping temperatures substantially within the limits recommended by ASHRAE. The control system saved $\$ 30,564$ per year and cost $\$ 56,824$ for a simple payback of 1.9 years.

Overall, the control software had the biggest energy-reduction impact. Rearranging the floor tiles produced the largest reduction in chilled-water energy consumption (followed by the control software), but confounding factors such as heat exchange with the building air-handling system or manual control of the cooling units could have contributed to the observed changes in chilled water consumption.

\section{Recommendations}

In future deployments, wireless sensors and control software should be installed initially. This will provide the highest initial savings and best initial return on investment, and 
provides detailed information about how to cost-effectively deployment of other best practices.

Additional studies of the impact of air distribution, particularly floor tile arrangement, is warranted given the large change in chilled water consumption that coincided with rearranging the floor tiles in this data center. Also, additional studies on the means and benefits of raising chilled water temperatures is warranted, given that return temperatures were increased by $7^{\circ} \mathrm{F}\left(3.9^{\circ} \mathrm{O}\right)$. Finally, additional study of the means and benefits of operating the data center at elevated temperatures, with free cooling, is warranted. For example, at this demonstration site, the datacenter is served by three terminal units from the main building air handler, which have air-side economizers. A study of how to best use the free cooling resources of the main air handler for the datacenter and integrating those cooling control actions with the control of the CRAHs is warranted since many datacenters are located in larger facilities where some cooling could be provided by conventional air handlers with air-side economizers.

\section{References}

1. ASHRAE, 2008, addendum to "2008 ASHRAE Environmental Guidelines for Datacom Equipment", Atlanta, GA.

2. Pinheiro, E., W. D. Weber, and L. A. Barroso, 2007, "Failure Trends in a Large Disk Drive Population," Proceedings of the $5^{\text {th }}$ USENIX Conference on File and Storage Technologies (FAST '07).

\section{Glossary}

CRAH: computer room air-handler

AHU: air-handling unit

ASHRAE: American Society of Heating, Refrigerating, and Air-Conditioning Engineers

HVAC: heating, ventilating, and air-conditioning

IT: information technology

PDU: power distribution unit

UPS: uninterruptible power supply

VFD: variable frequency drive 